\title{
Prognostic Significance of Altered Blood and Tissue Glutathione Levels in Head and Neck Squamous Cell Carcinoma Cases
}

\author{
Sami Ullah Khan, Ishrat Mahjabeen, Faraz Arshad Malik, Mahmood Akhtar \\ Kayani*
}

\begin{abstract}
Glutathione is a thiol compound that plays an important role in the antioxidant defense system of the cell and its deficiency leads to an increased susceptibility to oxidative stress and, thus, progression of many disease states including head and neck cancer. In the present study, alterations of glutathione levels were investigated in study cohort of 500 samples (cohort 1 containing 200 head and neck cancer blood samples along with 200 healthy controls and cohort II with 50 head and neck squamous cell carcinoma tissue samples along with 50 control tissues) by high performance liquid chromatography. The results indicated that mean blood glutathione levels were significantly reduced in head and neck cancer patients $(p<0.001)$ compared to respective controls. In contrast, the levels of glutathione total $(p<0.05)$ and glutathione reduced $(p<0.05)$ were significantly elevated in head and neck squamous cell carcinoma tissues compared to the adjacent cancer-free control tissues. In addition to this, pearson correlation performed to correlate different tissue glutathione levels (GSH) with clinical/ pathological parameters demonstrated a significant negative correlation between $p$ T-stage and GSH level $(r=-$ $\left.0.263^{* *} ; p<0.01\right)$, C-stage and GSH level $\left(r=-0.335^{* *} ; p<0.01\right)$, grade and GSH $\left(r=-0.329^{* *} ; p<0.01\right)$ and grade versus redox index $\left(r=-0.213^{* *} ; \mathrm{p}<0.01\right)$ in HNSCC tissues. Our study suggests that dysregulation of glutathione levels in head and neck cancer has the potential to predict metastasis, and may serve as a prognostic marker.
\end{abstract}

Keywords: Glutathione levels - redox index - prognostic marker - metastasis - HNC

Asian Pac J Cancer Prev, 15 (18), 7603-7609

\section{Introduction}

Head and neck squamous cell carcinoma (HNSCC) is a major cancer problem in Southern China, Pakistan, Thailand, India and Brazile. Overall prevalence of this disease is 12.3 per 100,000 out of total cancers treated in Pakistan (Bray et al., 2011; Pruegsanusak et al., 2012; Masood et al., 2013). HNSCC occurs through a complex multistage process which may involve exposure to a combination of carcinogens from cigarette smoking, alcohol consumption and chewing tobacco (Loyha et al., 2012). Although the mechanisms by which these risk factors enhance cancer risk remains largely unclear, however oxidative damage is believed to play a key role in carcinogenesis (Burlakova et al., 2010). Free radicals generated in tobacco smoke have been implicated in tobacco-induced carcinogenesis at numerous sites within the HNSCC (Mahjabeen et al., 2011). Among these radicals, reactive oxygen species (ROS) are potential carcinogens that facilitate mutagenesis, tumor promotion and progression. Although the extent of the contribution made by oxidative DNA damage has not been well defined, it appears that ROS-induced DNA damage can not only initiate carcinogenesis, but can also facilitate tumor progression (Kruk and Duchnik, 2014; Taya et al., 2014). Production and removal of these ROS within the cell is controlled by specific antioxidant defensive mechanisms (Oyagbemi et al., 2009; Nagamma et al., 2011).

These antioxidant defensive mechanisms include the enzymes superoxide dismutase, catalase, and glutathione peroxidase (GPx), as well as nonenzymatic compounds such as $\alpha$-tocopherol, $\beta$-carotene, vitamin C, and glutathione (Narasimhan et al., 2011; Manoharan et al., 2012; Yao et al., 2012). The major intracellular antioxidant glutathione represents a critical line of defense against oxidative stress and is considered to be a major thiol-disulphide redox buffer of cell. Average GSH concentration in the cytosol is $1-11 \mathrm{mmol} / \mathrm{l}$. This is far higher than most other redox active compounds (Schafer and Buettner, 2001). Therefore the redox state of glutathione reduced (GSH), glutathione oxidized (GSSG) has been used as indicator for the redox environment of the cell (Charles et al., 2006). Although there are several methods for estimating the intracellular redox index, the most important technique is the measurement of intracellular concentration of glutathione total $(\mathrm{GSHt})$, 
glutathione reduced (GSH), glutathione oxidized (GSSG) and the calculation of redox index by GSH/GSSG ratio (Gherghel et al., 2013). The intracellular GSH redox homeostasis is strictly regulated to govern cell metabolism and protect cells against oxidative stress and head and neck carcinogenesis (Richie et al., 2008).

The purpose of these experiments was to investigate extensive array of redox status indices: glutathione total (GSHt), glutathione reduced (GSH), glutathione oxidized (GSSG) and the calculation of redox index in HNSCC blood and tumor samples. Glutathione level and redox index were also correlated with clinical/histopathological parameters to assess the role of glutathione as biomarker of HNSCC.

\section{Materials and Methods}

\section{Apparatus}

PerkinElmer series 200 HPLC system (PerkinElmer Life and Analytical Sciences 710 Bridgeport Avenue Shelton, CT 06484-4794 USA) was used in this research. This HPLC system consists of analytical pump, autosampler, column oven, photo diode array (PDA) detector, fluorimeter, totalchrom chromatography data system (CDS) software.

\section{Samples collection and patient identifications}

The present population-based case-control study was conducted with a prior approval from ethical committees of both COMSATS Institute of Information Technology and collaborating hospitals. Two HNSCC patient groups were recruited in this study. The cohort 1 consisted of blood of 200 HNSCC cases and 200 matching normal healthy individuals as controls. The observed mean age of patients and controls was $45( \pm 16.35)$ and $43( \pm 32.23)$ years respectively. Non-significant difference was observed in case of age $(\mathrm{p}=0.9)$ and smoking status $(\mathrm{p}=0.4)$ between cancer cases and controls. In addition to this, a non-significant difference was observed in HNC patients for area of cancer $(p=0.08)$. The selection procedure for patients included confirmed histological diagnosis of HNSCC, no preoperative therapy and availability of complete follow-up data. The inclusion criterion for the controls was absence of prior history of cancer or precancerous lesions. Patients and controls suffering from any other familial disease (diabetes, blood pressure and cardiovascular impairment) were also excluded from this study.

Cohort 2 included tumors of $50 \mathrm{HNSCC}$ patients who had undergone surgery at Military Hospital (Rawalpindi, Pakistan) between 2009 and 2012. Demographic and clinical characteristics of study cohort 2 showed that median age of HNC cases and controls was 60 years with a range of 20-80. 50 tumors included $24(48 \%)$ cases of SCC of the larynx, $12(24 \%)$ cases of the pharynx and $14(28 \%)$ cases of SCC of the oral cavity .Most of the patients were in stage III of clinical and $\mathrm{T}$ staging with stage I of N staging. Most of the HNC patients had well differentiated tumors. All tumors were histologically confirmed as squamous cell carcinoma of head and neck and were graded as well differentiated, moderately differentiated and poorly differentiated. Samples of tumor core, the invasive edge of tumor and microscopically healthy mucosa (control) were obtained from each surgical section. Presence of tumor cells in the collected tissues was rectified by examination of frozen sections following haematoxylin and eosin stain by a consultant pathologist. Samples of control mucosa were obtained from macroscopically confirmed uninvolved healthy area $>2 \mathrm{~cm}$ away from the tumor.

\section{Blood sample preparation}

Blood sample was prepared by centrifugation at $600 \mathrm{~g}$ for 10 minutes. Separated aliquot was washed twice with phosphate buffer saline (PBS). Aliquot of the blood sample $(200 \mu \mathrm{l})$ was taken and $200 \mu \mathrm{l}$ of 5\% 5-Sulfosalicylic acid (SSA) solution was added. Each sample was vortexed vigorously and left for $10 \mathrm{~min}$ at $2-8^{\circ} \mathrm{C}$. After this the whole mixture was centrifuged at $10,000 \mathrm{~g}$ for $10 \mathrm{~min}$.

\section{Tissue sample preparation}

The tissue sample (100mg) was homogenized in $3 \mathrm{ml}$ buffer solution prepared by mixing of $10 \mathrm{mM}$ EDTA, $50 \mathrm{mM}$ NACLO4 and $0.1 \% \mathrm{H} 3 \mathrm{PO} 4$. Total protein was precipitated by adding $0.5 \mathrm{ml}$ metaphosphoric acid $(5 \% \mathrm{w} / \mathrm{v})$. The samples were vortexed for $20 \mathrm{mins}$ and centrifuged at $8000 \mathrm{~g}$ for $10 \mathrm{mins}$ at $4^{\circ} \mathrm{C}$. The supernatant was then transferred to auto-sampler vials of HPLC for analysis.

\section{Chromatographic settings \\ Column material \\ Column dimension \\ Flow rate \\ Fluorescence detection \\ MZ Inertsil ODS, $5 \mu \mathrm{m}$
$125 \mathrm{~mm} \times 4 \mathrm{~mm}$
$0.75-1.0 \mathrm{ml} / \mathrm{min}$
Excitation $385 \mathrm{~nm}$ and \\ Emission $515 \mathrm{~nm}$ \\ Injection volume \\ $20 \mu \mathrm{l}$ \\ Running time \\ Temperature}

\section{Glutathione total (GSHt) assay}

The sample was diluted with internal standard, reaction buffer and derivatization solution (o-phthalaldehyde precolumn) was mixed together. This mixture was incubated for $20 \mathrm{mins}$ at $60^{\circ} \mathrm{C} .100 \mu \mathrm{l}$ reaction buffer was added to this mixture which was incubated for 10 minutes at $2-8^{\circ} \mathrm{C}$ and then centrifuged for 10 minutes at $10,000 \mathrm{~g}$. $100 \mu \mathrm{l}$ of supernatant was added to $200 \mu \mathrm{l}$ reaction buffer in auto sampler-vials. $20 \mu \mathrm{l}$ of sample was then taken and injected in HPLC-system. One run lasted for 4 mins. The chromatograms were recorded by a fluorescence detector. The quantification was performed with EDTA-blood calibrator; the concentration was calculated by internal standard method and a standard curve of GSHt was then generated using a linear regression program (Microsoft Excel; Microsoft cooperation, Redmond,WA) as reported earlier (Gherghel et al., 2005).

\section{Glutathione reduced (GSH) assay}

Reduced glutathione was treated with $100 \mu$ l reaction buffer and $100 \mu$ l derivatisation solution (o-phthalaldehyde precolumn). This mixture was incubated for $20 \mathrm{mins}$ at 
$60^{\circ} \mathrm{C} .100 \mu \mathrm{l}$ reaction buffer was added to this mixture, incubated for $10 \mathrm{mins}$ at $2-8^{\circ} \mathrm{C}$ and centrifuged for 10 mins at $10,000 \mathrm{~g} .100 \mu \mathrm{l}$ of supernatant was added to $200 \mu \mathrm{l}$ reaction buffer in auto sampler-vial and $20 \mu \mathrm{l}$ of sample was then injected in the HPLC-system. One run lasted for 4 mins. The chromatograms were recorded by a fluorescence detector.The quantification was performed with EDTAblood calibrator; the concentration was calculated by internal standard method and a standard curve of GSHt was then generated using a linear regression program (Microsoft Excel; Microsoft cooperation, Redmond, WA) as reported previously (Gherghel et al., 2005).

The oxidized glutathione levels (GSSG= GSHt-GSH) and the redox index (defined as the GSH/GSSG ratio) were then calculated. Blood and tissue glutathione levels (GSHt,GSH, GSSG and redox index) were measured in $\mu \mathrm{mol} / \mathrm{l}$ and $\mathrm{nmol} / \mathrm{mg}$, respectively.

\section{Statistical analysis}

The results for the groups are expressed as mean \pm SE. Multivariate analysis was performed to determine the influence of age, gender, smoking status and area of cancer on HNSCC blood samples and tissue glutathione levels. For statistical analysis, the experimental values were compared with their corresponding controls. $\mathrm{P}$-values were calculated by chi-square test and ANOVA. Pearson correlation coefficient was used to calculated the correlation among glutathione levels and clinical/ histopathological parameters (*indicates the level of significance of pearson correlations as calculated by SPSS).

\section{Results}

Blood glutathione level [Glutathione total (GSHt), Glutathione reduced (GSH), Glutathione oxidized (GSSG)] and redox index was observed in 200 HNSCC patients and 200 control samples in study cohort 1 . Mean blood GSHt (912.94 $\pm 3.70 ; \mathrm{p}<0.001)$, GSH (823.35 \pm 4.50 ; $\mathrm{p}<0.01)$, GSSG $(89.59 \pm 2.22, \mathrm{p}<0.05)$ and redox index $(9.19 \pm 1.05 ; \mathrm{p}<0.01)$ levels were observed significantly lower in HNSCC samples compared to control samples, as shown in Table 1 and Figure 1.

Multiple regression analysis revealed that significantly lower level of GSHt ( $<<0.01)$ and GSH ( $<<0.01$ below 45 years and $\mathrm{p}<0.007$ above age 45 years) was observed in HNSCC in all age groups when compared with control groups. In case of gender, significant lower levels of GSHt, GSH, GSSG and redox index were observed in

Table 1. Blood and Tissue Glutathione Levels of HNSCC Patients

\begin{tabular}{|c|c|c|c|c|}
\hline \multirow[t]{2}{*}{ Glutathione } & \multicolumn{2}{|c|}{$\begin{array}{c}\text { Cohort } 1 \\
\text { Blood samples }\end{array}$} & \multicolumn{2}{|c|}{$\begin{array}{l}\text { Cohort } 2 \\
\text { Tumor tissue samples }\end{array}$} \\
\hline & $\begin{array}{l}\text { HNSCC } \\
\text { patients }\end{array}$ & $\begin{array}{l}\text { Controls } \\
\text { patients }\end{array}$ & $\begin{array}{c}\text { HNSCC } \\
\text { tissues }\end{array}$ & $\begin{array}{l}\text { Control } \\
\text { tissues }\end{array}$ \\
\hline GSHt & $912.94 \pm 3.70^{* * *}$ & $936.46 \pm 4.80$ & $39.43 \pm 0.40 *$ & $32.04 \pm 0.24$ \\
\hline GSH & $823.35 \pm 4.50 * *$ & $848.55 \pm 3.54$ & $29.67 \pm 0.85^{*}$ & $21.22 \pm 0.73$ \\
\hline GSSG & $89.59 \pm 2.22 *$ & $102.61 \pm 2.75$ & $9.76 \pm 0.39$ & $10.82 \pm 0.68$ \\
\hline \multicolumn{5}{|c|}{ GSH/GSSG, redox index } \\
\hline & $9.19 \pm 1.05^{* *}$ & $09.65 \pm 1.00$ & $3.03 \pm 0.22$ & $1.96 \pm 0.20$ \\
\hline
\end{tabular}

male and female HNSCC patients compared to male and female control samples. Moreover, significantly lower level of GSHt, GSH, GSSG and redox index was observed in smoker and non smoker HNSCC patients compared to smoker and non smoker control samples (Table 2). Significantly lower levels of GSHt $(\mathrm{p}<0.002)$, GSH $(\mathrm{p}<0.001)$, GSSG $(\mathrm{p}<0.004)$ and redox index $(\mathrm{p}<0.001)$ was observed in different areas of cancer.

A forward stepwise, pearson correlation was performed which revealed that age has a significant and negative correlation with GSH $\left(r=-0.233^{*} ; \mathrm{p}<0.05\right)$. No significant correlation was observed between age and other forms of blood glutathione (GSHt, GSSG, redox index) in HNSCC patients. In case of gender and smoking status, no significant correlation was observed with different forms of blood glutathione (GSHt, GSH, GSSG and redox index) in cancer patients. Additionally to explore glutathione-glutathione relationship, we observed a positive Pearson correlation between GSHt versus GSH $(0.800 * * * ; p<0.0001)$ and GSHt versus GSSG $\left(\mathrm{r}=0.636^{* * *}, \mathrm{p}<0.0001\right)$ in HNSCC patients. A positive correlation was observed between GSH versus redox index $\left(\mathrm{r}=0.343^{* *} ; \mathrm{p}<0.01\right)$ and negative correlation between GSSG versus redox index $(\mathrm{r}=-0.287 * * ; \mathrm{p}<0.01)$. An apparent inverse correlation was observed between GSHt versus redox index $(\mathrm{r}=-0.171 ; \mathrm{p}=0.09)$ and $\mathrm{GSH}$ versus GSSG ( $\mathrm{r}=-0.046 ; \mathrm{p}=0.72$ ). However, these correlations were statistically non-significant (Table 4).

In second part of this study, glutathione levels were observed in 50 squamous cell carcinoma of head and neck (HNSCC) tumor samples and compared with 50 control samples in study cohort 2. Mean tissue GSHt (39.43 \pm 0.40 ; $\mathrm{p}<0.05)$ and GSH $(29.67 \pm 0.85 ; \mathrm{p}<0.05)$ levels were observed significantly higher in HNSCC compared to controls. Whereas in case of mean tissue GSSG levels $(9.76 \pm 0.39, p=0.07)$ and redox index $(3.03 \pm 0.22 ; p=0.26)$ no significant difference was observed in HNSCC patients compared to controls (Table 1). Multiple regression analysis of study cohort 2 revealed that significantly higher mean values of GSHt $(\mathrm{p}<0.01)$ and GSH $(\mathrm{p}<0.01)$ were observed in all age groups of HNSCC patients when compared with control group. In case of different genders, significantly higher levels of GSHt, GSH, GSSG and redox index was observed in male and female HNSCC patients compared to male and female control samples. Moreover significantly higher levels of GSHt, GSH, GSSG and redox index were observed in smoker and non smoker HNSCC patients compared to smoker and non smoker control individuals (Table 3). Significantly higher levels of GSHt, GSH, GSSG and redox index were observed

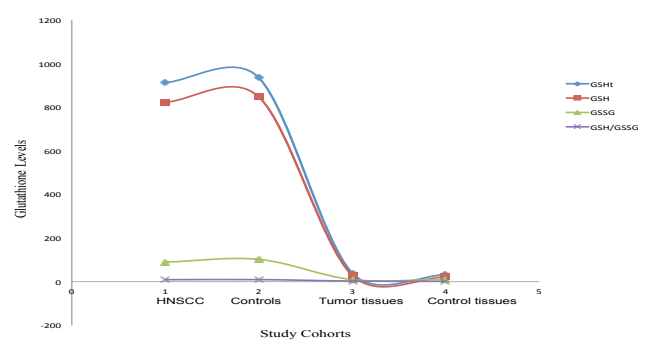

Figure 1. Scatter Plot Showing Blood and Tissue Glutathione Levels of HNSCC Patients and Controls 
Table 2. Comparison of Blood Glutathione Levels in Relation to Age, Gender and Smoking Status in HNSCC Patients and Controls

\begin{tabular}{|c|c|c|c|c|c|}
\hline Variables & & Glutathione & Control (Mean \pm SEM) & Patients $($ Mean \pm SEM) & p-value \\
\hline \multirow[t]{8}{*}{ Age } & \multirow[t]{4}{*}{$\leq 45$ years } & Glutathione total (GSHt) & $963 \pm 7.64$ & $921 \pm 3.89$ & $<0.01$ \\
\hline & & Glutathione reduced (GSH) & $934 \pm 5.33$ & $903 \pm 4.34$ & $<0.01$ \\
\hline & & Glutathione oxidized (GSSG) & $29 \pm 1.67$ & $18 \pm 1.03$ & $<0.14$ \\
\hline & & GSH/GSSG, redox index & $32.20 \pm 6.43$ & $50.17 \pm 5.25$ & $<0.14$ \\
\hline & \multirow[t]{4}{*}{$\geq 45$ years } & Glutathione total (GSHt) & $840 \pm 4.34$ & $811 \pm 4.22$ & $<0.01$ \\
\hline & & Glutathione reduced (GSH) & $821 \pm 4.13$ & $804 \pm 3.23$ & $<0.007$ \\
\hline & & Glutathione oxidized (GSSG) & $19 \pm 3.12$ & $7 \pm 1.33$ & $<0.2$ \\
\hline & & GSH/GSSG, redox index & $43.63 \pm 2.21$ & $114.86 \pm 2.34$ & $<0.26$ \\
\hline \multirow[t]{8}{*}{ Gender } & \multirow[t]{4}{*}{ Male } & Glutathione total (GSHt) & $954.34 \pm 6.95$ & $923.16 \pm 5.94$ & $<0.01$ \\
\hline & & Glutathione reduced (GSH) & $848.55 \pm 3.54$ & $823.35 \pm 4.50$ & $<0.01$ \\
\hline & & Glutathione oxidized (GSSG) & $105.78 \pm 3.17$ & $99.81 \pm 3.48$ & $<0.01$ \\
\hline & & GSH/GSSG, redox index & $8.02 \pm 3.20$ & $8.24 \pm 2.59$ & $<0.009$ \\
\hline & \multirow[t]{4}{*}{ Female } & Glutathione total (GSHt) & $920.62 \pm 5.30$ & $894.58 \pm 4.54$ & $<0.009$ \\
\hline & & Glutathione reduced (GSH) & $823.40 \pm 4.1$ & $804.70 \pm 2.40$ & $<0.008$ \\
\hline & & Glutathione oxidized (GSSG) & $97.22 \pm 4.8$ & $89.88 \pm 4.33$ & $<0.03$ \\
\hline & & GSH/GSSG, redox index & $8.46 \pm 2.29$ & $8.95 \pm 3.1$ & $<0.01$ \\
\hline \multirow[t]{8}{*}{ Smoking status } & \multirow[t]{4}{*}{ Smokers } & Glutathione total (GSHt) & $940.88 \pm 6.28$ & $899.30 \pm 4.33$ & $<0.01$ \\
\hline & & Glutathione reduced (GSH) & $834.30 \pm 3.21$ & $807.54 \pm 5.45$ & $<0.01$ \\
\hline & & Glutathione oxidized (GSSG) & $106.58 \pm 5.6$ & $91.76 \pm 8.51$ & $<0.04$ \\
\hline & & GSH/GSSG, redox index & $7.83 \pm 4.56$ & $8.80 \pm 3.12$ & $<0.03$ \\
\hline & \multirow[t]{4}{*}{ Non smokers } & Glutathione total (GSHt) & $935.15 \pm 5.00$ & $913.00 \pm 4.26$ & $<0.008$ \\
\hline & & Glutathione reduced (GSH) & $833.7 \pm 3.87$ & $817.60 \pm 2.85$ & $<0.006$ \\
\hline & & Glutathione oxidized (GSSG) & $101.45 \pm 3.14$ & $95.4 \pm 2.74$ & $<0.02$ \\
\hline & & GSH/GSSG, redox index & $8.21 \pm 2.70$ & $8.57 \pm 3.33$ & $<0.01$ \\
\hline
\end{tabular}

Table 3. Comparison of Tissue Glutathione Level in Relation to Age, Gender, and Smoking Status in HNSCC Patients and Controls

\begin{tabular}{|c|c|c|c|c|c|}
\hline \multicolumn{2}{|c|}{ Variables } & Glutathione & Control (Mean \pm SEM) & \multirow{2}{*}{$\frac{\text { Patients }(\text { Mean } \pm \text { SEM })}{20.13 \pm 0.45}$} & \multirow{2}{*}{$\frac{p \text {-value }}{<0.08}$} \\
\hline Age & $\leq 45$ years & Glutathione total (GSHt) & $15.25 \pm 0.33$ & & \\
\hline & & Glutathione reduced (GSH) & $11.35 \pm 0.75$ & $14.17 \pm 0.25$ & $<0.07$ \\
\hline & & Glutathione oxidized (GSSG) & $3.9 \pm 0.65$ & $5.96 \pm 0.56$ & $<0.1$ \\
\hline & & GSH/GSSG, redox index & $2.98 \pm 0.47$ & $2.82 \pm 0.45$ & $<0.01$ \\
\hline & $\geq 45$ years & Glutathione total (GSHt) & $16.79 \pm 0.21$ & $19.30 \pm 0.38$ & $<0.04$ \\
\hline & & Glutathione reduced (GSH) & $9.86 \pm 0.36$ & $15.50 \pm 0.57$ & $<0.1$ \\
\hline & & Glutathione oxidized (GSSG) & $6.93 \pm 0.57$ & $3.80 \pm 0.83$ & $<0.1$ \\
\hline & & GSH/GSSG, redox index & $1.44 \pm 0.17$ & $6.13 \pm 1.51$ & $<0.3$ \\
\hline \multirow[t]{8}{*}{ Gender } & Male & Glutathione total (GSHt) & $21.27 \pm 4.31$ & $16.5 \pm 5.20$ & $<0.08$ \\
\hline & & Glutathione reduced (GSH) & $9.97 \pm 3.66$ & $11.16 \pm 4.29$ & $<0.1$ \\
\hline & & Glutathione oxidized (GSSG) & $6.52 \pm 0.98$ & $5.11 \pm 0.69$ & $<0.07$ \\
\hline & & GSH/GSSG, redox index & $1.57 \pm 0.30$ & $7.27 \pm 4.25$ & $<0.3$ \\
\hline & Female & Glutathione total (GSHt) & $15.54 \pm 0.34$ & $19.25 \pm 0.28$ & $<0.08$ \\
\hline & & Glutathione reduced (GSH) & $10.23 \pm 0.01$ & $13.32 \pm 0.25$ & $<0.09$ \\
\hline & & Glutathione oxidized (GSSG) & $5.31 \pm 1.05$ & $5.93 \pm 0.40$ & $<0.03$ \\
\hline & & GSH/GSSG, redox index & $2.01 \pm 0.40$ & $2.42 \pm 0.28$ & $<0.05$ \\
\hline \multicolumn{6}{|c|}{ Smoking status } \\
\hline \multirow{4}{*}{\multicolumn{2}{|c|}{ Smokers }} & Glutathione total (GSHt) & $14.26 \pm 2.13$ & $19.33 \pm 3.11$ & $<0.05$ \\
\hline & & Glutathione reduced (GSH) & $12.89 \pm 2.29$ & $17.42 \pm 2.34$ & $<0.05$ \\
\hline & & Glutathione oxidized (GSSG) & $1.37 \pm 0.33$ & $1.91 \pm 0.29$ & $<0.1$ \\
\hline & & GSH/GSSG, redox index & $9.40 \pm 3.29$ & $9.12 \pm 3.65$ & $<0.01$ \\
\hline & Non smokers & Glutathione total (GSHt) & $15.91 \pm 4.30$ & $19.67 \pm 2.54$ & $<0.07$ \\
\hline & & Glutathione reduced (GSH) & $13.56 \pm 2.18$ & $17.29 \pm 1.38$ & $<0.06$ \\
\hline & & Glutathione oxidized (GSSG) & $2.35 \pm 0.79$ & $2.38 \pm 1.08$ & $<0.004$ \\
\hline & & GSH/GSSG, redox index & $2.38 \pm 0.45$ & $7.26 \pm 0.84$ & $<0.3$ \\
\hline
\end{tabular}

in different area of cancer while, GSH $(\mathrm{p}<0.001)$ and redox index $(\mathrm{p}<0.001)$ levels were significantly lower in different area of cancer compared to GSHt $(\mathrm{p}<0.01)$ and GSSG $(\mathrm{p}<0.01)$ level.

Pearson correlation was performed to correlate different tissue glutathione levels with clinical/ pathological parameters. Age was found significantly and negatively correlated with GSHt $(\mathrm{r}=0.38 * *, \mathrm{p}<0.01)$ and GSH $(\mathrm{r}=0.274 * * \mathrm{p}<0.01)$ while no significant correlation was observed between age versus GSSG ( $\mathrm{r}=-0.094$; $\mathrm{p}=0.62)$ and age versus redox index $(\mathrm{r}=0.062 ; \mathrm{p}<0.07)$. A significantly negative correlation was observed between pT-stage versus GSH level $\left(\mathrm{r}=-0.263^{* *} ; \mathrm{p}<0.01\right)$ and C-stage versus GSH level ( $\left.\mathrm{r}=-0.335^{* *} ; \mathrm{p}<0.01\right)$ in HNSCC tissues. However no significant correlation was observed between pT-satge versus GSSG $(r=0.120 ; \mathrm{p}=0.22)$, pTstage versus redox index $(\mathrm{r}=-0.31 ; \mathrm{p}=0.65), \mathrm{C}$-stage versus GSHt ( $r=-0.10 ; p=0.82), C$-stage versus GSSG ( $r=-0.038$; $\mathrm{p}=0.42), \mathrm{C}$-stage versus redox index $(\mathrm{r}=0.03 ; \mathrm{p}=0.71)$, $\mathrm{pN}$ versus GSHt $(\mathrm{r}=0.017 ; \mathrm{p}=0.88)$, $\mathrm{pN}$ versus $\mathrm{GSH}(\mathrm{r}=$ 
Table 4. Correlation Between Blood and Tissue Glutathione Levels and Clinico-pathological Characteristics in HNSCC Patients

\begin{tabular}{|c|c|c|c|c|c|c|c|c|c|}
\hline \multirow[t]{2}{*}{ Variable } & & \multicolumn{2}{|r|}{ GSHt } & \multicolumn{2}{|r|}{ GSH } & \multicolumn{2}{|r|}{ GSSG } & \multicolumn{2}{|c|}{ Redox index } \\
\hline & & $\mathrm{r}$ & $95 \% \mathrm{CI}$ & $\mathrm{r}$ & $95 \% \mathrm{CI}$ & $\mathrm{r}$ & $95 \% \mathrm{CI}$ & $\mathrm{r}$ & $95 \% \mathrm{CI}$ \\
\hline \multirow[t]{6}{*}{ Cohort 1} & Age & -0.164 & $-943.11,-947.25$ & $-0.233 *$ & $-840.81,-828.54$ & 0.026 & $-103.77,-94.28$ & -0.068 & $-9.77,-6.39$ \\
\hline & Gender & 0.014 & $-889.83,-873.13$ & -0.50 & $-787.78,-774.17$ & 0.072 & $-50.61,-40.035$ & -0.021 & $+42.39,-48.83$ \\
\hline & Smoking Status & -0.061 & $-943.05,-927.21$ & -0.13 & $-840.74,-828.49$ & 0.067 & $-103.71,-94.22$ & -0.113 & $-9.73,-6.71$ \\
\hline & GSHt & - & - & $0.800^{\text {**** }}$ & $-95.75,+105.26$ & $0.636^{* * *}$ & $-830.04,-842.27$ & -0.171 & $+918.72,-935.47$ \\
\hline & GSH & - & - & - & - & -0.046 & $+728.09,+743.22$ & $0.343^{* *}$ & $+820.26,-832.93$ \\
\hline & GSSG & & & & & - & - & $-0.287^{* * *}$ & $+85.46,-96.42$ \\
\hline \multirow[t]{10}{*}{ Cohort II } & Age & $-0.38^{* *}$ & $-19.73,-18.36$ & $-0.274^{* *}$ & $-10.68,-10.18$ & 0.094 & $-7.51, \pm 6.44$ & 0.062 & $-0.231,-0.153$ \\
\hline & Gender & 0.139 & $+31.00,+38.71$ & 0.190 & $+39.35,+47.23$ & 0.125 & $+49.93,+57.59$ & -0.184 & $+49.76,+57.59$ \\
\hline & Smoking Status & 0.134 & $-0.049,-0.234$ & $-0.202^{*}$ & $+42.7,+52.9$ & 0.067 & $-8.92,-9.20$ & -0.09 & $-7.34,-8.44$ \\
\hline & pT stage & -0.057 & $-18.18,-17.07$ & $-0.263^{* *}$ & $-9.54,-8.83$ & 0.120 & $-6.28,-5.18$ & -0.31 & $+0.931,+1.46$ \\
\hline & C stage & -0.10 & $-18.12,-16.96$ & $-0.335^{* *}$ & $-9.48,-8.74$ & -0.038 & $-6.22,-5.08$ & -0.03 & $+0.99,+1.56$ \\
\hline & pNstage & 0.017 & $-20.05,-19.00$ & -0.121 & $-11.40,-10.77$ & 0.073 & $-8.15,-7.11$ & 0.029 & $-0.93,-0.468$ \\
\hline & Grade & -0.092 & $-18.37,-17.27$ & $-0.329^{* * *}$ & $-9.69,-9.088$ & 0.99 & $-6.49,-5.37$ & $-0.213^{* *}$ & $+0.776,+1.22$ \\
\hline & GSHt & & & 0.192 & $+7.93,+8.9$ & $0.88^{* * *}$ & $+11.65,+12.12$ & $-0.71^{* * *}$ & $+18.22,+19.42$ \\
\hline & GSH & & & & & $-0.279^{* * *}$ & $+2.84+4.06$ & $0.447^{* * * *}$ & $+10.17,+10.60$ \\
\hline & GSSG & & & & & & & $-0.907^{* * * *}$ & $+6.31,+7.57$ \\
\hline
\end{tabular}

$-0.121 ; \mathrm{p}=0.66), \mathrm{pN}$ versus $\mathrm{GSSG}(\mathrm{r}=0.073 ; \mathrm{p}=0.046)$ and $\mathrm{pN}$ versus redox index $(\mathrm{r}=0.029 ; \mathrm{p}=0.45)$. A significantly negative correlation was observed between grade versus GSH $\left(\mathrm{r}=-0.329^{* *} ; \mathrm{p}<0.01\right)$ and grade versus redox index $\left(\mathrm{r}=-0.213^{* *} ; \mathrm{p}<0.01\right)$. In addition to this statistically non-significant correlation was observed between grade versus GSHt $(\mathrm{r}=-0.092 ; \mathrm{p}=0.17)$ and grade versus GSSG $(\mathrm{r}=0.99 ; \mathrm{p}<0.17)$. Additionally to explore glutathioneglutathione relationship in HNSCC, we observed a significantly positive correlation between GSHt versus GSSG $\left(r=0.88^{* * *} ; \mathrm{p}<0.001\right)$ and significantly negative correlation between GSHt versus redox index ( $\mathrm{r}=-0.71 * * *$; $\mathrm{p}<0.001)$ in HNSCC. We also observed a significantly positive correlation between GSH versus redox index $\left(\mathrm{r}=0.447^{* * *} ; \mathrm{p}<0.001\right)$ and significant negative correlation between GSH versus GSSG $\left(r=-0.279^{* *} ; \mathrm{p}<0.01\right)$ and GSSG versus redox index $\left(\mathrm{r}=-0.907^{* * *} ; \mathrm{p}<0.001\right)$ (Table $4)$.

\section{Discussion}

Free radicals are implicated in the pathogenesis of a multistage process of head and neck carcinogenesis, which are proposed to cause DNA base alterations, strand breaks, damage to tumour suppressor genes and an enhanced expression of proto-oncogenes (Nisha et al., 2008; Mahjabeen et al., 2011). In addition to these burst of reactive oxygen species (ROS) and reactive nitrogen species (RNS) has also been implicated in the development of different cancers including HNSCC (Kruk and Duchnik, 2014; Valluru et al., 2014). To safeguard the integrity of genome, humans have well defined defense mechanism to prevent body against stress and ROS, among which the most important one is glutathione which directly reduces reactive oxygen species and acts as first line of defense against oxidative stress (Rasheed et al., 2007; Nisha et al., 2008).

In this present study we assessed the glutathione total (GSHt), glutathione reduced (GSH), glutathione oxidized (GSSG) and redox index in HNSCC and compared with controls. In first part, we observed that mean blood glutathione levels are significantly reduced in head and neck cancer compared with respective controls. Our results are in agreement with earlier studies which have demonstrated that glutathione levels differ in patients of head and neck malignancies and this depletion could be due to imbalance in free-radical and antioxidant homeostasis in body fluids during carcinogenesis (Singh et al., 2008; Waly et al., 2012; Shetty et al., 2013). The other plausible explanation for decreased levels of glutathione observed in head and neck cancer patients is possibly GSH, being exhausted as a main low molecular weight antioxidant in cellular protection (Komatsu et al., 2008; Trachootham et al., 2009). Increased utilization of glutathione can act as an indicator of increased oxidative stress and ROS in HNSCC patients. Our results are in agreement with earlier studies which showed that levels of glutathione decrease in blood of the breast cancer when compared with control subjects (Yeh et al., 2006).

In second part of this study we used 50 HNSCC tissue samples and 50 non cancerous control tissue samples and observed significantly higher levels of GSHt and GSH in HNSCC tissue samples compared with control tissue samples. No significant difference in levels of GSSG and redox index was observed in HNSCC tissue samples when compared with non cancerous control tissues. The elevated levels of GSHt and GSH have also been observed in chronic myelogenous leukemia, acute myelogenous leukemia, or chronic lymphocytic leukemias (Singh et al., 2008) which support our results. The increased levels of glutathione in HNSCC tissues may be result of stress and excess need of glutathione in turn increase tumor load, which reduce anti-apoptotic mechanism and cell death and results in un-controlled cell growth and division resulting in cancer pathogenesis (Balendiran et al., 2004). The increased levels of glutathione in tumor resist radiotherapy and anti-cancer drug resistance (Gupta et al., 2010). Present results from this study have shown that levels of glutathione are decreased in blood of head and neck cancer patients and elevated in tissues when compared to the respective controls. These decreased and elevated levels of glutathione may deregulate cytochrome P450 (Wahid et al., 2013) and glutathione expression which are important mechanisms involved in carcinogenesis and mutagenesis. 
GSH is among the most efficient substance which can be used by cells and tissues in their defense against oxidative stress and is representative of redox environment of the cell (Cacciatore et al., 2010). Age and disease, however, act to decrease the amount of GSH available in the organism (Erden-Inal et al., 2002). Our results have shown a significantly negative correlation between age and both GSH levels and redox index in both study groups. In HNSCC patients, age is strongly associated with increased oxidative stress and reduced antioxidant stress. In case of gender and glutathione levels, no difference was observed between male and female patients with respect to blood glutathione levels in either of these study groups. It seems that gender has a less consistent effect on blood glutathione levels than other confounding variables such as age and more research is necessary to further address this issue.

Our study also showed that there was a decrease in tissue GSH level and redox index as the pT-stage, C-stage and grade of HNSCC tumor increased. This decreased level of GSH with increase in stage of HNSCC may be due to increased utilization of GSH and increased level of oxidative stress in advance stages of carcinogenesis (Singh et al., 2008). This would imply that the antioxidant defense system of these patients is defective and unable to cope with free radicals' overload. We also observed that decreased GSH results in increased GSSG with a concomitant decrease in redox index in both HNSCC study cohorts. GSH is depleted in various tissues with increase in levels of GSSG which reduce the GSH/ GSSG ratio. Increased GSSG concentration in tissues and accelerated release from the cell is considered to be a signal of oxidative stress and could contribute to free radical diseases such as HNSCC (Muchova et al., 2007). Variations in GSH, GSSG level and redox status in carcinogenesis are thought to function in control of fundamental processes such as gene expression, cell proliferation or apoptosis. Thus if redox index can be detected in vivo in association with pathology or toxicity, this finding may provide an important link to underlying mechanism.

In conclusion our study has demonstrated a significant association between blood glutathione levels and HNSCC. This study also confirms the dysregulation of glutathione level in HNSCC when compared with normal tissues. There is increased dysregulation in more metastatic disease when compared with primary tumors. The results obtained from this study suggest that altered blood and tissue glutathione levels may be used as prognostic marker and ancillary screening tool for individual with risk of HNSCC.

\section{Acknowledgements}

All authors wish to acknowledge the patients and control individuals who contributed to this research work. We are also thankful to hospital staff (Nuclear Oncology and Radiotherapy Institute Islamabad (NORI) Pakistan, for their help and cooperation.This study was supported by a grant from Higher Education Commission, Islamabad (Pakistan). The authors declare that they have no conflict of interests.

\section{References}

Balendiran GK, Dabur R, Fraser D (2004). The role of glutathione in cancer. Cell Biochem Funct, 22, 343-52.

Bray F, Ren JS, Masuyer E, et al (2012). Estimates of global cancer prevalence for 27 sites in the adult population in 2008. Int J Cancer, 132, 1133-45.

Burlakova EB, Zhizhina GP, Gurevich SM, et al (2010). Biomarkers of oxidative stress and smoking in cancer patients. J Can Res Ther, 6, 47-53.

Cacciatore I, Cornacchia C, Pinnen F, Mollica A, Di Stefano A (2010). Prodrug approach for increasing cellular glutathione levels. Molecules, 15, 1242-64.

Lu C, Margaret RS, Hua Z, et al (2006). Association between Glutathione-S-transferase II polymorphism and survival in patients with advanced non small cell lung carcinoma (NSCLC). Cancer, 106, 441-7.

Erden-Inal M, Sunal E, Kanbak G (2002). Age-related changes in the glutathione redox system. Cell Biochem Funct, 20, 61-6.

Gherghel D, Griffiths HR, Hilton EJ, Cunliffe IA, Hosking SL (2005). Systemic reduction in glutathione levels occurs in patients with primary open-angle glaucoma. Invest Ophthalmol Vis Sci, 46, 877-83.

Gherghel D, Mroczkowska S, Qin L (2013). Reduction in blood glutathione levels occurs similarly in patients with primary-open angle or normal tension glaucoma. Glaucoma, 54, 3333-9.

Gupta A, Bhatt MLB, Misra MK (2010). Assessment of free radical-mediated damage in head and neck squamous cell carcinoma patients and after treatment with radiotherapy. Indian J Biochem Biophys, 47, 96-9.

Komatsu D, Kato M, Nakayama J, et al (2008). NADPH oxidase 1 plays a critical mediating role in oncogenic Ras-induced vascular endothelial growth factor expression. Oncogene, 27, 4724-32.

Kruk J, Duchnik E (2014). Oxidative stress and skin diseases: possible role of physical activity. Asian Pac J Cancer Prev, 15, 561-8.

Loyha K, Vatanasapt P, Promthet S, Parkin DM (2012). Risk factors for oral cancer in northeast Thailand. Asian Pac J Cancer Prev, 13, 5087-90.

Mahjabeen I, Baig RM, Masood N, et al (2011). OGG1 Gene sequence variation in head and neck cancer patients in Pakistan. Asian Pacific J Cancer Prev, 12, 2779-83.

Manoharan S, Singh AK, Suresh K, et al (2012). Antitumor initiating potential of andrographolide in 7,12-dimethylbenz(a)anthracene induced hamster buccal pouch carcinogenesis. Asian Pac J Cancer Prev, 13, 5701-8.

Masood N, Yasmin A, Kayani MA (2013). Genetic deletions of GSTM1 and GSTT1 in head and neck cancer: review of the literature from 2000 to 2012. Asian Pac J Prev, 14, 3535-9.

Muchova J, Garaiova I, Sustrova M, et al (2007). The redox state of glutathione in erytjrocytes of individuals in down syndrome. Bratisl Lek Listry, 108, 70-4.

Narasimhan R, Vaithiyanathan M, Janardanam V (2011). Neuroprotective effect of sesamol in glioma induced in rats. Bio Med Int, 2, 22-7.

Nagamma, Anjaneyulu, Baxi, Dayaram P, Singh P (2011). Cigarette smoking and lipid peroxidation and antioxidant status in cancer patients from western Nepal. Asian Pac J Cancer Prev, 12, 313-6.

Nisha, Sachdeva A, Lal H (2008). Some oxidative stress related parameters in patients with head and neck carcinoma. Indian $J$ Clin Biochem, 23, 38-40.

Oyagbemi AA, OI Azeez, AB Saba (2009). Interactions between reactive oxygen species and cancer: the roles of natural dietary antioxidants and their molecular mechanisms of 
action. Asian Pac J Cancer Prev, 10, 535-44.

Pruegsanusak K, Peeravut S, Leelamanit V, et al (2012). Survival and prognostic factors of different sites of head and neck cancer: an analysis from Thailand. Asian Pac J Cancer Prev, 13, 885-90.

Rasheed MH, Beevi SS, Geetha A (2007). Enhanced lipid peroxidation and nitric oxide products with deranged antioxidant status in patients with head and neck squamous cell carcinoma. Oral Oncology, 43, 333-8.

Richie JP, Kleinman W, Marina P, Muscat JE (2008). Blood iron, glutathione, and micronutrient levels and the risk of oral cancer. Nutr Cancer, 60, 474-82.

Schafer FQ, Buettner GR (2001). Redox environment of cell as viewed through the redox state of the glutathione disulphide/ glutathione couple. Free Radic Biol Med, 30, 1191-212.

Shetty SR, Babu S, Kumari S, et al (2013). Serum glutathione levels in oral leukoplakia and oral squamous cell carcinoma-a clinicopathological study. Am J Cancer Prev, 1, 1-3.

Singh, YP, Sachdeva OP, Aggarwal SK, Chugh K, Harbans L (2008). Blood glutathione levels in head and neck malignances. Indian J Clinc Biochem, 23, 290-2.

Taya S, Punvittayagul C, Inboot W, Fukushima S, Wongpoomchai $\mathrm{R}$ (2014). Cleistocalyx nervosum extract ameliorates chemical-induced oxidative stress in early stages of rat hepatocarcinogenesis. Asian Pac J Cancer Prev, 15, 2825 30 .

Trachootham D, Alexandre J, Huang P (2009). Targeting cancer cells by ROS-mediated mechanisms: a radical therapeutic approach? Nat Rev Drug Discov, 7, 579-91.

Valluru L, Dasari S, Wudayagiri R. (2014). Role of free radicals and antioxidants in gynecological cancers: current status and future prospects. Oxid Antioxid Med Sci, 13, 15-26.

Wahid M, Mahjabeen I, Baig RM, Kayani MA (2013). Expression of CYP1A1 and GSTP1 in human brain tumor tissues in Pakistan. Asian Pac J Cancer Prev, 14, 7187-91.

Waly MI, Ali A, Guizani N, et al (2012). Pomegranate (Punica granatum) peel extract efficacy as a dietary antioxidant against azoxymethane-induced colon cancer in rat. Asian Pac J Cancer Prev, 13, 4051-5.

Yao L, Ji G, Gu A, Zhao P, Liu N (2012). An updated pooled analysis of glutathione s-transferase genotype polymorphisms and risk of adult gliomas. Asian Pac J Cancer Prev, 13, 157-63.

Yeh CC, Hou MF, Wu SH et al (2006). A study of glutathione status in the blood and tissues of patients with breast cancer. Cell Biochem Funct, 24, 555-9. 